\title{
Impact of remuneration and organizational factors on completing preventive manoeuvres in primary care practices
}

\author{
Simone Dahrouge PhD, William E. Hogg MD MClSc, Grant Russell MBBS PhD, Meltem Tuna PhD, \\ Robert Geneau PhD, Laura K. Muldoon MD, Elizabeth Kristjansson PhD, John Fletcher MD
}

\begin{abstract}
- ABSTRACT
Background: Several jurisdictions attempting to reform primary care have focused on changes in physician remuneration. The goals of this study were to compare the delivery of preventive services by practices in four primary care funding models and to identify organizational factors associated with superior preventive care.

Methods: In a cross-sectional study, we included 137 primary care practices in the province of Ontario (35 fee-for-service practices, 35 with salaried physicians [community health centres] 35 practices in the new capitation model [family health networks] and 32 practices in the established capitation model [health services organizations]). We surveyed 288 family physicians. We reviewed 4108 randomly selected patient charts and assigned prevention scores based on the proportion of eligible preventive manoeuvres delivered for each patient.

Results: A total of 3284 patients were eligible for at least one of six preventive manoeuvres. After adjusting for patient profile and contextual factors, we found that, compared with prevention scores in practices in the new capitation model, scores were significantly lower in fee-for-service practices ( $\beta$ estimate for effect on prevention score $=-6.3,95 \%$ confidence interval $[\mathrm{Cl}]-11.9$

to -0.6$)$ and practices in the established capitation model $(\beta=-9.1,95 \% \mathrm{Cl}-14.9$ to -3.3$)$ but not for those with salaried remuneration ( $\beta=$ $-0.8,95 \% \mathrm{Cl}-6.5$ to 4.8$)$. After accounting for physician characteristics and organizational structure, the type of funding model was no longer a statistically significant factor. Compared with reference practices, those with at least one female family physician $(\beta=8.0,95 \% \mathrm{Cl} 4.2$ to 11.8), a panel size of fewer than 1600 patients per full-time equivalent family physician $(\beta=6.8$, $95 \% \mathrm{Cl} 3.1$ to 10.6$)$ and an electronic reminder system ( $\beta=4.6,95 \% \mathrm{Cl} 0.4$ to 8.7 ) had superior prevention scores. The effect of these three factors was largely but not always consistent across the funding models; it was largely consistent across the preventive manoeuvres.

Interpretation: No funding model was clearly associated with superior preventive care. Factors related to physician characteristics and practice structure were stronger predictors of performance. Practices with one or more female physicians, a smaller patient load and an electronic reminder system had superior prevention scores. Our findings raise questions about reform initiatives aimed at increasing patient numbers, but they support the adoption of information technology.
\end{abstract}

$\mathrm{P}$ rimary care providers are increasingly interested in ensuring that preventive health care be part of their work routines. ${ }^{1}$ This reorientation fits with the evidence that recommendations from family practitioners increase substantially the likelihood of patients undergoing preventive manoeuvres, ${ }^{2}$ whereas the lack of such recommendations has been linked with patient noncompliance. ${ }^{3,4}$

Studies evaluating adherence to recommended preventive care suggest that the most pervasive barriers rest with the organization of the health care system and the practice itself, such as the absence of external financial incentives for the work done and the lack of a reminder system in the office. ${ }^{3,5-9}$

Countries attempting to reform their delivery of primary care and improve the delivery of preventive services have often directed their efforts in finding alternatives to the traditional fee-forservice model, in which providers receive payment for each service provided. There are two predominant alternative funding models: capitation (providers receive a fixed lump-sum payment per patient per period, independent of the number of services performed) and salaried remuneration. Some health care systems blend components of fee for service with either of these models or offer additional incentives for reaching defined qualityof-care targets. Despite considerable rhetoric, there is little evidence to point to the remuneration models associated with superior delivery of primary care services. ${ }^{10}$ The complexity of health
Competing interests:

Simone Dahrouge was a consultant to the Conference Board of Canada on a study evaluating Family Health Teams in Ontario. No competing interests declared by the other authors.

Disclaimer: John Fletcher is a Deputy Editor for CMAJ. He was not involved in the editorial decisionmaking process for this article.

This article has been peer reviewed.

Correspondence to: Dr. Simone Dahrouge, sdahrouge@bruyere.org

CMAJ 2012. DOI:10.1503 /cmaj.110407 
care systems makes the evaluation of models through international comparisons difficult.

In Canada, the province of Ontario has four primary care funding models (Table 1). This variety provides a unique opportunity to compare primary care delivery under different funding models in a single jurisdiction. At the time this study was conducted, more than $90 \%$ of the provincial population was served by one of the four models. The models vary by funding structure, but also by organizational structure and stated priorities. ${ }^{11}$

We conducted this study to compare the delivery of preventive services by practices in the four funding models and to identify organizational factors associated with superior preventive care. This study is part of a larger evaluation of primary care models in Ontario funded by the Ontario Ministry of Health and Long-Term Care through its Primary Health Care Transition Fund.

\section{Methods}

\section{Study design}

We used a cross-sectional design whereby we conducted chart audits to examine the perfor- mance of six preventive manoeuvres in primary care practices in the province of Ontario (Table 2). Data collection took place between October 2005 and June 2006. Details about the methodology of the entire project are reported elsewhere. ${ }^{12}$

\section{Sample size}

Calculation of the sample size for the main study was based on the ability to detect a difference of 0.5 standard deviation in the disease prevention score (the primary outcome), with an intraclass correlation of 0.2 , an $\alpha$ value of 0.05 and $\beta$ value of 0.20 . The recommendation was to sample 40 practices per funding model and 30 patient charts per practice. Because of timing constraints, we had to limit the enrolment to 35 practices per model.

Eligible practices had to have belonged to their funding model for at least one year, provide general primary care services and have at least half of their primary care providers agree to participate in the study. For enrolment, we targeted all 94 practices in the new capitation model (family health networks), the 65 practices in the established capitation model (health services organizations), the 51 practices with salaried physicians (community health cen-

Table 1: Characteristics of the four primary care models in the province of Ontario in 2005/06

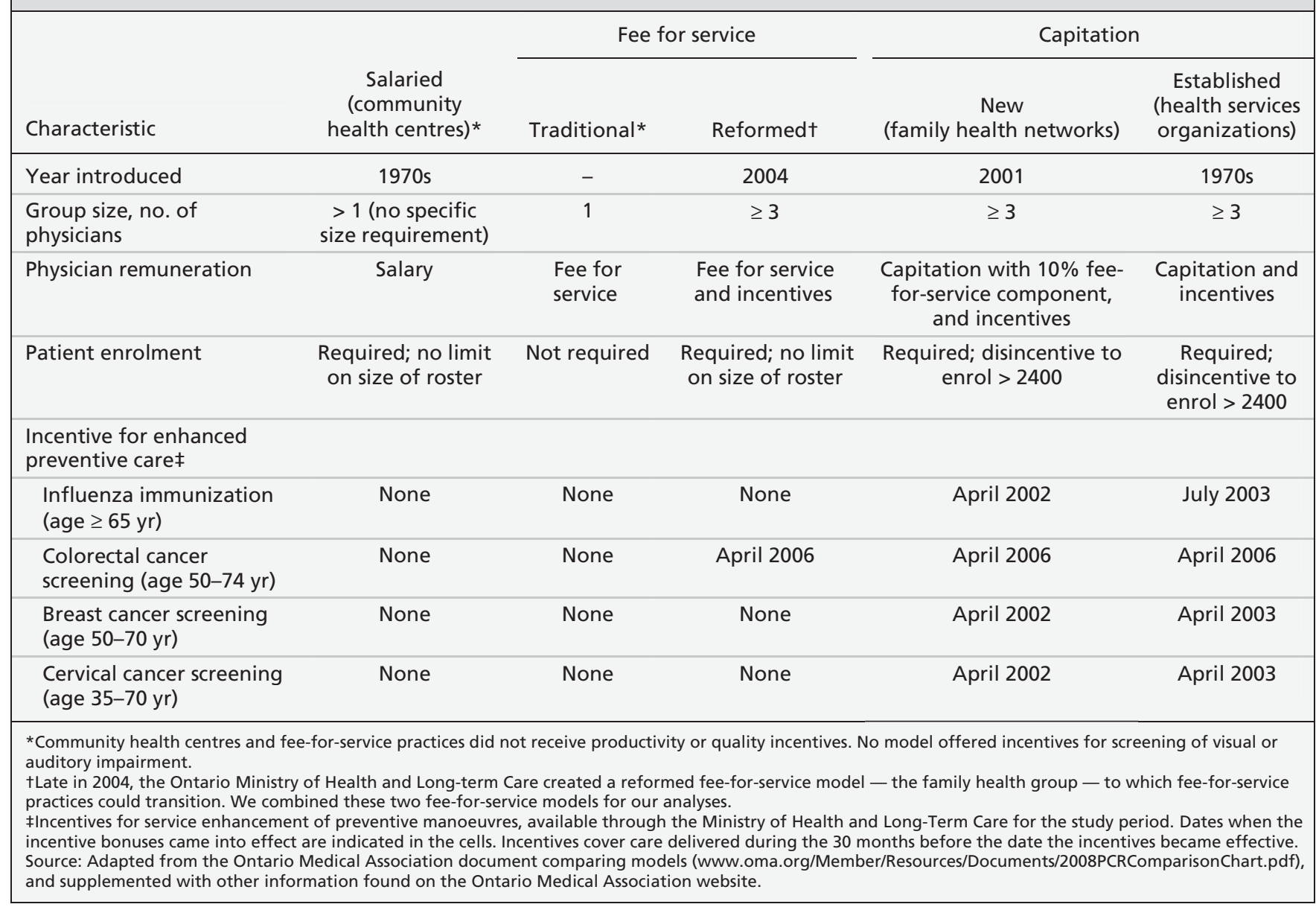


tres) and 155 randomly selected traditional and reformed fee-for-service practices that were eligible for this study. We continued to enrol practices until we reached our target of 35 per model or until time precluded further enrolment activity. Recruitment was done through mail invitation, with repeated follow-up using the Dillman method. ${ }^{13}$

In practices that had paper files, we selected the fifth chart after a predetermined distance until we identified 30 eligible health records. In practices that used electronic records, we used a random-number generator until 30 eligible charts were identified. Eligible patients had to be at least 17 years of age, to be a patient of a participating provider, to have been with the practice at least two years and to have visited the practice in the year before the chart review. ${ }^{12}$

\section{Outcome measures}

In each practice, the practice manager or head physician completed an organizational survey that was based on the Primary Care Assessment Tool / Adult Edition ${ }^{14}$ and was supplemented by additional questions about practice structure. Participating physicians completed a provider survey that captured information about their age, sex, past training and experience. Data from the organizational and physician surveys were used to understand the factors associated with better preventive care.

Chart audits were used to assess the performance of six preventive manoeuvres (Table 2), which were based on recommendations from the Canadian Task Force on Preventive Health Care ${ }^{15}$ and which had been used in another study. ${ }^{16}$ For each patient, we calculated an overall prevention score by dividing the number of manoeuvres performed by the number of manoeuvres for which the patient was eligible within the previous 24 months and then multiplying by 100 . For example, for a 55-year-old woman eligible for the three cancer screening manoeuvres, her score would be based on the number of cancer screening manoeuvres performed divided by three and multiplied by 100 . For a 75 -year-old man eligible for the hearing and eye examinations and the influenza vaccination, his score would similarly be calculated as the number of manoeuvres performed divided by three and multiplied by 100 .

\section{Statistical analysis}

We compared practice characteristics (patient and physician profiles, contextual factors and organizational structure) across the four funding models using the $\mathrm{F}$ statistic (analysis of variance) and the $\chi^{2}$ test, as appropriate. We performed multilevel linear regression analyses to evaluate the bivariate relation between each of these characteristics and the prevention score. Analyses were performed at the individual patient level. We obtained the overall association between each factor and the prevention score for the entire study population while accounting for the clustered nature of the data (patients nested within the provider/practice).

Using multilevel linear regression analyses to account for the clustered nature of the data, we first compared the prevention score (dependent variable) between models of care (main independent variable) unadjusted for other factors. We then adjusted, incrementally, for patient profile and contextual factors, and then physician profile. Because patients were not linked to their providers in the surveys, physician profiles were aggregated to practice-level variables. The addition of successive terms to the analyses sought to uncover the degree to which the differences between funding models

Table 2: Preventive manoeuvres evaluated in the study*

\begin{tabular}{|c|c|c|c|c|}
\hline Strategy & Manoeuvres & Eligible patients & $\begin{array}{l}\text { Recommended } \\
\text { frequency }\end{array}$ & $\begin{array}{c}\text { Score } \\
\text { attributed }+\end{array}$ \\
\hline Influenza immunization & $\begin{array}{l}\text { Administration of influenza } \\
\text { vaccine }\end{array}$ & $\begin{array}{l}\text { People at increased } \\
\text { risk of influenza }\end{array}$ & Annual & 1 \\
\hline Cervical cancer screening & Papanicolaou smear & Females 17-69 yr & $\begin{array}{l}\text { Annual (high risk) or } \\
\text { every } 3 \text { years }\end{array}$ & 1 \\
\hline Breast cancer screening & $\begin{array}{l}\text { Mammography and clinical } \\
\text { breast examination }\end{array}$ & Women 50-69 yr & Annual or biannual & $\begin{array}{c}0.5 \text { per } \\
\text { manoeuvre }\end{array}$ \\
\hline Colorectal cancer screening & $\begin{array}{l}\text { Fecal occult blood testing or } \\
\text { flexible sigmoidoscopy }\end{array}$ & People $\geq 50$ yr & Annual or biannual & 1 \\
\hline Visual impairment screening & Eye examination & People $\geq 65$ yr & Unspecified & 1 \\
\hline $\begin{array}{l}\text { Auditory impairment } \\
\text { screening }\end{array}$ & Hearing examination & People $\geq 65$ yr & Unspecified & 1 \\
\hline $\begin{array}{l}\text { *Patient charts were audited to che } \\
\text { tEach patient was assigned a prever } \\
\text { number of manoeuvres for which th } \\
100 \text { (if all eligible manoeuvres were }\end{array}$ & $\begin{array}{l}\text { ompletion of eligible preventive } n \\
\text { re that was calculated by dividin } \\
\text { tt was eligible and then multiplyi } \\
\text { ned). }\end{array}$ & $\begin{array}{l}\text { uvres in the } 24 \text { month } \\
\text { umber of manoeuvre } \\
100 \text {; the score ranged }\end{array}$ & $\begin{array}{l}\text { the start of the study. } \\
\text { med within the previous } 2 \\
\text { if no eligible manoeuvres }\end{array}$ & $\begin{array}{l}\text { ths by the } \\
\text { performed) to }\end{array}$ \\
\hline
\end{tabular}


could be explained by each of these factors. We retained variables significant at the $p<0.05$ level.

To assess whether organizational features of the practices accounted for variation in prevention scores, we continued to build on the analysis by adding variables that captured the organizational features. Again, only variables significant at the $p<0.05$ level were retained. To determine the transferability of the results across funding models, we repeated the analysis with the same variables in each of the four models individually. Finally, to determine whether the impact of each organizational feature contained in that analysis was driven by a subset of the preventive manoeuvres, we repeated the analysis using multilevel binary logistic regression analysis in which each preventive manoeuvre was the dependent variable.

The linearity of continuous variables was verified, and where appropriate, the variable was categorized. There were no missing values in the chart data, which captured patient profile and outcome data. Each variable from the surveys contained no more than $3.6 \%$ of missing data. ${ }^{17}$ To avoid casewise deletion, we imputed missing values of continuous variables using Statistics Canada's nearest-neighbourhood technique (whereby a missing value for an individual is attributed the value derived from a group of individuals who have a similar profile), ${ }^{18}$ and we added a separate category for the missing values of a discrete variable for all multivariable regression analyses.

\section{Ethics approval}

The study design was approved by the Ottawa Hospital Research Ethics Board.

\section{Results}

We recruited 35 (23\%) of the fee-for-service practices, $35(37 \%)$ of the practices in the new capitation model, 32 (49\%) of those in the established capitation model and 35 (69\%) of those in the salaried model. Secondary analysis of data from provincial health administrative databases, available for practices in the nonsalaried models only, showed that the physician profile from the participating practices in each of the three nonsalaried models was similar to that of all physicians practising in the respective models in Ontario. ${ }^{12} \mathrm{We}$ abstracted 4108 charts, 3284 of which were for patients eligible for at least one of the six preventive manoeuvres. The prevention score was nonnormally distributed across 18 scores; the mean score overall was 61 (range 0 to 100).

Table 3 shows the practice characteristics across the funding models. The associations between these characteristics and the overall prevention score are shown in Table 4.
After adjusting for patient profile and contextual factors, we found that, compared with the prevention scores in practices in the new capitation model, scores were significantly lower in practices in the fee-for-service and established capitation models but not in practices in the salaried model (Table 5, Analysis B). Practices in the salaried model had scores higher only than those in practices in the established capitation model. After further adjustment for physician factors, only practices in the fee-for-service and established capitation models had prevention scores significantly lower than those in the new capitation model (Table 5, Analysis C).

Three factors not related to patient profile were independently associated with the prevention score (Table 5, Analysis D). When these factors were included in the analysis, the funding model variables were no longer statistically significant. Practices in which we could document the presence of at least one female family physician (based on providers' responses) had higher prevention scores than practices without a documented female family physician ( $\beta$ estimate of effect on overall prevention score $=8.0,95 \%$ confidence interval [CI] 4.2 to 11.8 ). Practices with an average panel size (number of patients per fulltime equivalent family physician) of fewer than 1600 patients had higher prevention scores than practices with a larger average panel size $(\beta=6.8$, 95\% CI 3.1 to 10.6). Finally, practices with an electronic reminder system for recommended patient care (e.g., screening) had higher prevention scores than practices not using such a system $(\beta=$ $4.6,95 \%$ CI 0.4 to 8.7$)$. The presence of an electronic health record substituted for the reminder system in the analysis conferred about the same effect size (4.6, 95\% CI 0.8 to 8.4 ).

The effect of these three practice-related factors was largely but not always consistent across the funding models (data not shown). The effect was largely consistent across the preventive manoeuvres (Table 6).

\section{Interpretation}

We observed important differences in the prevention activities between primary care practices in the four funding models in Ontario. However, when organizational factors were considered, we found that practice structure rather than funding arrangements was the primary determinant of the delivery of evidence-based preventive health care. Across the whole sample, superior prevention scores were associated with the presence of at least one female family physician, a smaller panel size (fewer than 1600 patients per full-time equivalent family physician) and the presence of an electronic reminder system. 
Table 3: Characteristics of practices across primary care funding models

\begin{tabular}{|c|c|c|c|c|}
\hline \multirow[b]{2}{*}{ Characteristic* } & \multicolumn{4}{|c|}{ Primary care modelt } \\
\hline & Salaried & $\begin{array}{l}\text { Fee for } \\
\text { service }\end{array}$ & $\begin{array}{l}\text { New } \\
\text { capitation }\end{array}$ & $\begin{array}{l}\text { Established } \\
\text { capitation }\end{array}$ \\
\hline Patient profile & $n=856$ & $n=849$ & $n=827$ & $n=752$ \\
\hline Age, yr, mean $\ddagger$ & 43.7 & 47.9 & 48.4 & 50.0 \\
\hline Female, $\% \ddagger$ & 68.0 & 59.0 & 58.9 & 54.2 \\
\hline Insured in Ontario, \% & 95.3 & 99.8 & 99.9 & 100.0 \\
\hline$>1$ visit in previous year, $\% \ddagger$ & 87.0 & 84.8 & 80.0 & 76.2 \\
\hline \multicolumn{5}{|l|}{ Chronic diseases } \\
\hline No. of chronic diseases per patient, mean $\ddagger$ & 0.33 & 0.35 & 0.40 & 0.44 \\
\hline Hypertension, \%§ & 19.1 & 21.0 & 24.5 & 24.6 \\
\hline Diabetes mellitus, \% & 7.8 & 6.6 & 7.6 & 8.6 \\
\hline Coronary artery disease, \%§ & 4.8 & 5.4 & 6.9 & 8.8 \\
\hline Congestive heart failure, $\%$ & 0.8 & 1.4 & 1.4 & 2.0 \\
\hline$\geq 1$ chronic disease, $\% \S$ & 23.2 & 25.2 & 28.6 & 29.6 \\
\hline Contextual factor & $n=35$ & $n=35$ & $n=35$ & $n=32$ \\
\hline$<10 \mathrm{~km}$ to hospital, $\%$ & 71.4 & 85.3 & 94.1 & 86.7 \\
\hline Rurality index $\geq 4$, \%§ & 68.6 & 51.4 & 85.7 & 87.5 \\
\hline Family physician profile & $n=108$ & $n=58$ & $n=80$ & $n=42$ \\
\hline No. of years since graduation, mean $\ddagger$ & 19.2 & 22.3 & 22.6 & 28.5 \\
\hline Presence of $\geq 1$ female family physician, $* * \% \neq$ & 85.3 & 48.5 & 48.6 & 25.0 \\
\hline Foreign trained, \%†† & 9.3 & 17.2 & 2.5 & 14.3 \\
\hline $\begin{array}{l}\text { College of Family Physicians of Canada } \\
\text { certification, } \%\end{array}$ & 79.4 & 84.5 & 77.9 & 67.5 \\
\hline Organizational structure & $n=35$ & $n=35$ & $n=35$ & $n=32$ \\
\hline No. of nurses per FTE family physician, mean $\ddagger$ & 0.9 & 0.2 & 0.6 & 0.7 \\
\hline Panel size $<1600$ patients per FTE family physician, \%¥ & 84.8 & 48.4 & 58.1 & 42.9 \\
\hline Booking interval for routine visit, min, mean $\neq$ & 24.8 & 12.9 & 13.9 & 13.6 \\
\hline \multicolumn{5}{|l|}{ Staffing } \\
\hline Solo practice, $\% \S$ & 0 & 25.7 & 37.1 & 37.5 \\
\hline Presence of nurse-practitioner(s), $\% \ddagger$ & 100.0 & 8.6 & 31.0 & 18.8 \\
\hline No. of nurses, mean $\ddagger$ & 2.7 & 0.6 & 2.0 & 1.1 \\
\hline \multicolumn{5}{|l|}{ Information technologył‡ } \\
\hline Electronic health records, \%§ & 28.6 & 14.3 & 57.1 & 43.8 \\
\hline Electronic system for patient scheduling, \%§ & 97.1 & 62.9 & 71.4 & 68.8 \\
\hline $\begin{array}{l}\text { Electronic reminder system for recommended patient } \\
\text { care (e.g., screening), \%†† }\end{array}$ & 25.7 & 14.3 & 45.7 & 28.1 \\
\hline $\begin{array}{l}\text { Electronic interface to external laboratory/diagnostic } \\
\text { imaging, } \% \S\end{array}$ & 45.7 & 14.3 & 51.4 & 40.6 \\
\hline \multicolumn{5}{|c|}{$\begin{array}{l}\text { Note: } \mathrm{Cl}=\text { confidence interval, } \mathrm{FTE}=\text { full-time equivalent. } \\
{ }^{*} \text { Characteristics shown were obtained from chart data, provider survey data and organizational survey data and used in the analyses. } \\
\text { tThe four models are known by their financing arrangement: salaried (community health centre), fee for service (fee-for-service } \\
\text { practices), new capitation model (family health networks) and established capitation model (health services organizations). See } \\
\text { Table } 1 \text { for more information. } \\
\text { fCharacteristic was significantly different }(p<0.001) \text { across the models; } \chi^{2} \text { or } \mathrm{F} \text { test (analysis of variance [ANOVA]), as appropriate. } \\
\text { SCharacteristic is significantly different }(p<0.01) \text { across the models; } \chi^{2} \text { or } \mathrm{F} \text { test (ANOVA), as appropriate. } \\
\text { qRurality index is based on the Rurality Index of Ontario and ranges from } 0-100 \text {. } \\
* * \text { The presence of a female family physician could only be determined from the respondents. Since at least } 50 \% \text { of the providers } \\
\text { were required to participate, it is likely that some practices in which not all providers participated were wrongly coded as not } \\
\text { having a female family physician. } \\
++ \text { Characteristic is significantly }(p<0.05) \text { different across the models; } \chi^{2} \text { test or } \mathrm{F} \text { test (ANOVA), as appropriate. } \\
\neq \neq \text { For information technology factors, practices were asked to report whether the practice site had implemented, to any extent, } \\
\text { each of the technologies listed. }\end{array}$} \\
\hline
\end{tabular}


The positive effect of female primary care providers on the delivery of preventive care has been reported previously, but it is unclear how this is mediated. Some studies documented a more general positive benefit of female pro- viders on preventive care, ${ }^{19,20}$ whereas others concluded that sex concordance between patients and their physicians led to better performance of sex-specific preventive manoeuvres among women. ${ }^{21,22}$ We could not evaluate the

Table 4: Association between characteristics of practices and overall prevention score

\begin{tabular}{|c|c|}
\hline Characteristic & $\begin{array}{l}\beta \text { estimate for effect } \\
\text { on overall prevention } \\
\text { score* }^{*}(95 \% \mathrm{Cl})\end{array}$ \\
\hline \multicolumn{2}{|l|}{ Patient profile } \\
\hline Age (per additional year) & $-0.6(-0.7$ to -0.5$) \dagger$ \\
\hline Female (v. male) & $24.4(21.5$ to 27.3$) \dagger$ \\
\hline Insured in Ontario (v. not insured) & $11.7(-1.5$ to 24.9$)$ \\
\hline$>1$ visit in previous year (v. 1 or no visits) & $8.3 \quad(4.6$ to 12.0$) \dagger$ \\
\hline \multicolumn{2}{|l|}{ Chronic diseases } \\
\hline No. of chronic diseases per patient (per additional disease) & $-8.5(-10.2$ to -6.8$) \dagger$ \\
\hline Hypertension (v. no hypertension) & $-14.0(-17.0$ to -11.0$) \dagger$ \\
\hline Diabetes mellitus (v. no diabetes) & $-10.6(-15.1$ to -6.1$) \dagger$ \\
\hline Coronary artery disease (v. no coronary artery disease) & $-14.4(-19.3$ to -9.5$) \dagger$ \\
\hline Congestive heart failure (v. no congestive heart failure) & $-13.6(-23.7$ to -3.6$) \ddagger$ \\
\hline$\geq 1$ chronic disease (v. no chronic disease) & $-15.9(-18.7$ to -13.0$) \dagger$ \\
\hline \multicolumn{2}{|l|}{ Contextual factor } \\
\hline$<10 \mathrm{~km}$ to hospital (v. greater distance) & $2.4 \quad(-4.5$ to 9.2$)$ \\
\hline Rurality index $\geq 4$ (v. lower index) & $-7.1(-12.8$ to -1.3$) \S$ \\
\hline \multicolumn{2}{|l|}{ Family physician profile } \\
\hline No. of years since graduation (per additional year) & $-0.43(-0.74$ to -0.12$) \neq$ \\
\hline Presence of $\geq 1$ female family physician ( $v$. no female physicians) & $14.8(10.2$ to 19.4$) \dagger$ \\
\hline Foreign trained (v. trained in Canada) & $0.8(-11.1$ to 12.8$)$ \\
\hline $\begin{array}{l}\text { College of Family Physicians of Canada certification } \\
\text { (v. no certification) }\end{array}$ & $-1.8(-8.8$ to 5.2$)$ \\
\hline \multicolumn{2}{|l|}{ Organizational structure } \\
\hline No. of nurses per FTE family physician (per additional nurse) & $-0.2(-6.9$ to 6.6$)$ \\
\hline Panel size < 1600 patients per FTE family physician (v. larger panel) & $9.0 \quad$ (4.0 to 14.1$) \dagger$ \\
\hline Booking interval for routine visit, min (per additional minute) & $0.7 \quad(0.3$ to 1.1$) \dagger$ \\
\hline \multicolumn{2}{|l|}{ Staffing } \\
\hline Solo practice (v. group practice) & $-10.6(-16.4$ to -4.8$) \ddagger$ \\
\hline Presence of nurse-practitioner(s) (v. no nurse-practitioner) & $5.6 \quad(0.4$ to 10.9$) \S$ \\
\hline No. of nurses (per additional nurse) & $1.0(-0.5$ to 2.4$)$ \\
\hline \multicolumn{2}{|l|}{ Information technology } \\
\hline Electronic health records (v. paper files) & $4.9(-0.5$ to 10.3$)$ \\
\hline Electronic system for patient scheduling (v. no such system) & $7.6 \quad(1.7$ to 13.5$) \S$ \\
\hline $\begin{array}{l}\text { Electronic reminder system for recommended patient care } \\
\text { (e.g., screening) (v. no such system) }\end{array}$ & $3.9(-1.8$ to 9.6$)$ \\
\hline $\begin{array}{l}\text { Electronic interface to external laboratory/diagnostic imaging } \\
\text { (v. no such interface) }\end{array}$ & $5.9 \quad(0.7$ to 11.3$) \S$ \\
\hline \multicolumn{2}{|c|}{$\begin{array}{l}\text { Note: } \mathrm{Cl}=\text { confidence interval, } \mathrm{FTE}=\text { full-time equivalent. } \\
{ }^{*} \text { The } \beta \text { estimates were derived from the multilevel linear regression analyses to evaluate the bivariate relation between each of the } \\
\text { characteristics listed and the overall prevention score. For example, the prevention score (out of } 100 \text { ) for women was } 24.4 \text { higher than } \\
\text { the score for men on average, whereas older individuals had lower prevention scores (by } 0.6 \text { for each additional year of age). } \\
+p<0.001 ; \chi^{2} \text { or } \mathrm{F} \text { test (ANOVA), as appropriate. } \\
\neq p<0.01 ; \chi^{2} \text { or } \mathrm{F} \text { test (ANOVA), as appropriate. } \\
\S p<0.05 ; \chi^{2} \text { or } \mathrm{F} \text { test (ANOVA), as appropriate. }\end{array}$} \\
\hline
\end{tabular}


effect of sex concordance because physicianspecific information was not linked directly to patient data and instead was aggregated at the practice level. However, our finding of a positive association between the presence of one or more female physicians and preventive care was not limited to female-specific manoeuvres, which suggests a more general, cross-cutting effect on preventive care.

We cannot exclude the possibility that features of the practices in which female family physicians chose to practice (other than those available for analysis in the study) were responsible for the higher prevention scores. The presence of a female physician could be ascertained only from the providers' responses. Because only $50 \%$ of providers in a practice were required to participate in the study for the practice to be eligible, some practices that had female physicians who did not participate in the study may have been wrongly classified as not having any female physicians. The effect of this error

Table 5: Differences in prevention scores across funding models in multilevel regression analyses

\begin{tabular}{|c|c|c|c|c|c|}
\hline Variable & $\begin{array}{l}\text { Overall } \\
\text { prevention } \\
\text { score* } \\
(95 \% \mathrm{Cl})\end{array}$ & \multicolumn{4}{|c|}{ Multilevel regression analysis; $\beta$ estimate for effect on prevention score $\dagger(95 \% \mathrm{Cl})$} \\
\hline Intercept & & $2.4(59.5$ to 69.2$)$ & 46.5 (42.1 to 51.0$)$ & 41.9 (37.3 to 46.6$)$ & 40.1 (36.2 to 44.0$)$ \\
\hline \multicolumn{6}{|l|}{ Funding modelt† } \\
\hline New capitation & 65 (62 to 67) & ref & ref & ref & \\
\hline Fee for service & 58 (55 to 61$)$ & $-6.4(-13.2$ to 0.5$)$ & $-6.3(-11.9$ to -0.6$)$ & $-6.4(-11.7$ to -1.1$)$ & \\
\hline Established capitation & 52 (49 to 55$)$ & $-12.0(-19.0$ to -5.0$)$ & $-9.1(-14.9$ to -3.3$)$ & $-6.8(-12.2$ to -1.3$)$ & \\
\hline \multicolumn{6}{|l|}{ Patient profile } \\
\hline Males, all ages & & & ref & ref & ref \\
\hline Females 17-49 yrł‡ & & & 34.6 (31.5 to 37.7$)$ & 34.3 (31.2 to 37.4$)$ & 34.5 (31.4 to 37.6$)$ \\
\hline \multicolumn{6}{|l|}{ Family physician profile } \\
\hline $\begin{array}{l}\text { Presence of } \geq 1 \text { female family } \\
\text { physician }\end{array}$ & & & & $9.8 \quad(5.6$ to 14.0$)$ & $8.0 \quad(4.2$ to 11.8$)$ \\
\hline \multicolumn{6}{|l|}{ Organizational structure } \\
\hline $\begin{array}{l}\text { Panel size }<1600 \text { patients per } \\
\text { FTE family physician }\end{array}$ & & & & & 6.8 (3.1 to 10.6$)$ \\
\hline $\begin{array}{l}\text { Presence of electronic } \\
\text { reminder system }\end{array}$ & & & & & $4.6 \quad(0.4$ to 8.7$)$ \\
\hline
\end{tabular}

Note: $\mathrm{Cl}$ = confidence interval, FTE = full-time equivalent, ref = reference category

* Each patient was assigned a prevention score that was calculated by dividing the number of manoeuvres performed by the number of manoeuvres for which the patient was eligible within the previous 24 months and then mulitplying by 100; the score ranged from 0 (if no eligible manoeuvres were performed) to 100 (if all eligible manoeuvres were performed).

tThe $\beta$ estimates were derived from multilevel linear regression analyses. Only statistically significant variables $(p<0.05)$ were retained in the model.

¥Analysis A: Only funding model variables were forced into the equation, with no adjustment for other factors. Compared with the prevention score for practices in the new capitation model, the score was significantly lower for practices in the established capitation model, whereas the score in the salaried model was superior to that in both the fee-for-service model and the established capitation model.

$\S$ Analysis B: Factors considered were variables in analysis A plus contextual factors (rurality index $\geq 4$, nearest hospital $<10 \mathrm{~km}$ ) and patient profile (sex, age, public insurance and number of chronic diseases). Significant variables entered in the equation were age-sex interactions; contextual factors were not significant. In this analysis, the prevention scores were significantly lower for the fee-for-service practices and the practices in the established capitation model than for the practices in the new capitation model, whereas the salaried model had a superior score to the established capitation model only (results not shown).

ПAnalysis C: Factors considered were variables in analysis B plus all of the variables contained under "family physician profile" in Table 3. Significant variables entered in the equation were age-sex interaction and presence of $\geq 1$ female family physician in the practice. As in Analysis B, prevention scores in this analysis were significantly lower for the fee-for-service practices and the practices in the established capitation model than for practices in the new capitation model. Scores for the salaried model were not statistically different from those for the other funding models (results not shown).

**Analysis D: Factors considered were variables in analysis C plus all of the variables contained under "organizational structure" in Table 3. Variables significantly associated with the prevention score and retained in the equation were age-sex interaction, presence of $\geq 1$ female family physician in the practice, number of patients per FTE physician and presence of electronic reminder system; organizational factors were not significant. Using the variable "electronic health records" instead of electronic reminder system had a similar effect size $(4.6,95 \% \mathrm{Cl} 0.8$ to 8.4$)$.

††The four models are known by their financing arrangement: salaried (community health centres), fee for service (fee-for-service practices), new capitation model (family health networks) and established capitation model (health services organizations). See Table 1 for more information.

$\ddagger \ddagger T h e ~ \beta$ estimates are very high because the scores in these age/sex groups are driven by the high adherence to recommended guidelines for breast and cervical cancer screening. 
would be to underestimate the impact of having a female family physician in the practice.

Our finding that busier practices had lower overall prevention scores than practices with smaller patient loads was consistent with findings from other studies in which time constraints, competing demands and opportunity costs were pervasive barriers to quality preventive care. ${ }^{23,24}$ In Ontario, the standard base capitation rate for a patient is reduced by $50 \%$ for additional patients over 2400 enrolled. Our results suggest that the quality of preventive care may be compromised at patient loads below this number. Ontario and other Canadian provinces have a shortage of family physicians, and pressure to meet patient demands with inadequate resources is resulting in ever-increasing patient loads. ${ }^{25,26}$ Further work is required to establish a benchmark for a patient number that results in better preventive care.

Physicians have reported a need for reminder systems to support their preventive care, ${ }^{3,5}$ and these tools have been associated with improved care in several studies. ${ }^{7,827} \mathrm{We}$ found that the presence of an electronic reminder system was positively associated with prevention scores. We could not determine whether this association was because the system was being used to identify eligible patients for preventive manoeuvres or whether the implementation of information technology indicated practice innovation and an orientation to quality.

Several studies have shown that the lack of financial incentives to support the additional work involved in promoting preventive care is a barrier to improving preventive care. ${ }^{69,23,28,29}$ Several regions have implemented such incentives, but the evidence supporting their impact remains scarce and inconclusive. ${ }^{30,31}$ In Ontario, incentives to send reminders to patients to obtain preventive care and inducements to achieve greater patient coverage of preventive care have recently been implemented. Practices in each of the two capitation models were eligible for the same incentives during the study period. We could not assess whether these financial inducements affected the likelihood of delivering care. However, because the incentives and the time frame during which they were offered were the same, the incentives alone cannot explain why the prevention score was lower for practices in the established capitation model than for practices in the new capitation model.

\section{Limitations}

The cross-sectional nature of this study allowed us to measure associations but not ascertain causality. We identified three practice-related factors that were independently associated with superior preventive care. However, we could not establish whether these factors led directly to improved care or whether they were a measure of some other feature of the practice that was not captured in the study. The change from fee-for-service payment to capitation funding has been voluntary, and family physicians who chose one model over another may have differed in some way that affected their attention to preventive medicine. This would be a greater concern if we had detected significant differences in preventive care associated with type of funding model after accounting for organizational features of the practices.

As with any study, the extent of data collection is finite. We know from previous studies that the quality of preventive care is associated with attributes of primary care that we could not assess, such as the quality of the patient-provider relationship, the duration and continuity of the relationship, ${ }^{32}$ the organization's culture (i.e., the importance or focus it places on preventive care) ${ }_{29}^{29}$ and the providers' knowledge and beliefs. ${ }^{33}$ The nearest-neighbour technique used to impute missing values is a single imputation technique that can lead to distorted estimates (if the assumptions on which the imputation is based are flawed) and to inflated precision. ${ }^{34}$ Finally, we aggregated physician characteristics to the practice level, which probably reduced our

\begin{tabular}{|c|c|c|c|c|c|c|}
\hline \multirow[b]{2}{*}{ Factor } & \multicolumn{6}{|c|}{ Preventive manoeuvre; odds ratio $(95 \% \mathrm{Cl})$} \\
\hline & $\begin{array}{l}\text { Cervical cancer } \\
\text { screening }\end{array}$ & $\begin{array}{l}\text { Breast cancer } \\
\text { screening }\end{array}$ & $\begin{array}{l}\text { Influenza } \\
\text { vaccination }\end{array}$ & $\begin{array}{c}\text { Colorectal } \\
\text { cancer screening }\end{array}$ & $\begin{array}{c}\text { Hearing } \\
\text { examination }\end{array}$ & $\begin{array}{c}\text { Eye } \\
\text { examination }\end{array}$ \\
\hline $\begin{array}{l}\text { Presence of } \geq 1 \text { female } \\
\text { family physician }\end{array}$ & $1.7(1.2$ to 2.4$)$ & $1.3(0.8$ to 2.1$)$ & $1.4(0.9$ to 2.0$)$ & $1.6(1.1$ to 2.2$)$ & $0.9(0.5$ to 1.9$)$ & $1.3(0.7$ to 2.2$)$ \\
\hline $\begin{array}{l}\text { Panel size }<1600 \text { patients } \\
\text { per FTE family physician }\end{array}$ & $1.6(1.2$ to 2.2$)$ & $1.3(0.8$ to 2.0$)$ & $1.4(1.0$ to 2.2$)$ & $1.3(0.9$ to 1.9$)$ & 1.9 (1.0 to 3.8$)$ & 1.6 (0.9 to 2.7$)$ \\
\hline $\begin{array}{l}\text { Presence of electronic } \\
\text { reminder system }\end{array}$ & $1.2(0.8$ to 1.7$)$ & $1.7(1.0$ to 2.8$)$ & $1.3(0.9$ to 2.0$)$ & $1.2(0.8$ to 1.7$)$ & $2.3(1.1$ to 4.7$)$ & $1.6(0.9$ to 2.9$)$ \\
\hline
\end{tabular}


ability to detect associations between these factors and preventive care.

\section{Conclusion}

No funding model was clearly associated with superior preventive care. Factors related to physician characteristics and practice structure were stronger predictors of performance. Superior prevention scores were associated with the presence of at least one female family physician in the practice, a smaller panel size (fewer than 1600 patients per full-time equivalent physician) and the presence of an electronic reminder system. The fact that these associations were largely consistent across the funding models and across individual preventive manoeuvres supports their relevance to improving the delivery of high-quality primary care services.

\section{References}

1. Russell GM. Is prevention unbalancing general practice? Med J Aust 2005;183:104-5.

2. McGregor SE, Hilsden RJ, Li FX, et al. Low uptake of colorectal cancer screening $3 \mathrm{yr}$ after release of national recommendations for screening. Am J Gastroenterol 2007;102:1727-35.

3. Sarfaty M, Wender R. How to increase colorectal cancer screening rates in practice. CA Cancer J Clin 2007;57:354-66.

4. Klabunde CN, Vernon SW, Nadel MR, et al. Barriers to colorectal cancer screening: a comparison of reports from primary care physicians and average-risk adults. Med Care 2005;43:939-44.

5. Guerra CE, Schwartz JS, Armstrong K, et al. Barriers of and facilitators to physician recommendation of colorectal cancer screening. J Gen Intern Med 2007;22:1681-8.

6. Klabunde CN, Lanier D, Breslau ES, et al. Improving colorectal cancer screening in primary care practice: innovative strategies and future directions. J Gen Intern Med 2007;22:1195-205.

7. Hung DY, Rundall TG, Crabtree BF, et al. Influence of primary care practice and provider attributes on preventive service delivery. Am J Prev Med 2006;30:413-22.

8. Hudson SV, Ohman-Strickland P, Cunningham R, et al. The effects of teamwork and system support on colorectal cancer screening in primary care practices. Cancer Detect Prev 2007;31:417-23.

9. Anderson KK, Sebaldt RJ, Lohfeld L, et al. Views of family physicians in southwestern Ontario on preventive care services and performance incentives. Fam Pract 2006;23:469-71.

10. Devlin RA, Sarma S, Hogg W. Remunerating primary care physicians: emerging directions and policy options for Canada. Healthc $Q 2006 ; 9: 34-42$.

11. Muldoon L, Rowan MS, Geneau R, et al. Models of primary care service delivery in Ontario: Why such diversity? Healthc Manage Forum 2006;19:18-23.

12. Dahrouge S, Hogg W, Russell G, et al. The Comparison of Models of Primary Care in Ontario study (COMP-PC): methodology of a multifaceted cross-sectional practice-based study. Open Med 2009;3:e149-64.

13. Dillman DA. Mail and telephone surveys: the total design method. New York (NY): John Wiley and Sons Inc.; 1978.

14. Shi L, Starfield B, Xu J. Validating the Adult Primay Care Assessment Tool. J Fam Pract 2001;50:E1. Available: www.jfponline $. c 0 m /$ Pages.asp?AID=2157\&UID= $($ accessed 2010 Oct. 25$)$.

15. Canadian Task Force on Preventive Health Care. Recommendations for preventive health care. Ottawa $(\mathrm{ON})$ : The Task Force; 2005.

16. Hogg W, Lemelin J, Graham ID, et al. Improving prevention in primary care: evaluating the effectiveness of outreach facilitation. Fam Pract 2008;25:40-8.

17. Shrive FM, Stuart H, Quan H, et al. Dealing with missing data in a multi-question depression scale: a comparison of imputation methods. BMC Med Res Methodol 2006;6:57.

18. St-Pierre M, Béland Y. Imputation of proxy respondents in the Canadian Community Health Survey. Statistical Society of Canada Annual Meeting; 2002 May 26-29; Hamilton, Ont.

19. Flocke SA, Gilchrist V. Physician and patient gender concordance and the delivery of comprehensive clinical preventive services. Med Care 2005;43:486-92.

20. Henderson JT, Weisman CS. Physician gender effects on preventive screening and counseling: an analysis of male and female patients' health care experiences. Med Care 2001;39:1281-92.

21. Ahmad F, Stewart DE, Cameron JI, et al. Rural physicians' perspectives on cervical and breast cancer screening: a genderbased analysis. J Womens Health Gend Based Med 2001;10: 201-8.

22. Franks P, Bertakis KD. Physician gender, patient gender, and primary care. J Womens Health (Larchmt) 2003;12:73-80.

23. Brotons C, Bjorkelund C, Bulc M, et al. Prevention and health promotion in clinical practice: the views of general practitioners in Europe. Prev Med 2005;40:595-601.

24. Crabtree BF, Miller WL, Tallia AF, et al. Delivery of clinical preventive services in family medicine offices. Ann Fam Med 2005;3:430-5.

25. Ontario Ministry of Health and Long-Term Care. 500,000 more Ontarians with access to a family doctor as result of investments in family doctors. Toronto (ON): The Ministry; 2007. Available: www.health.gov.on.ca/english/media/news_releases/archives/nr_07 /jun/nr_20070621.html (accessed 2011 Nov. 21).

26. Wootton J. My practice is full and I can't take any new patients. Can J Rural Med 2007;12:203-4.

27. Stone EG, Morton SC, Hulscher ME, et al. Interventions that increase use of adult immunization and cancer screening services: a meta-analysis. Ann Intern Med 2002;136:641-51.

28. Dulai GS, Farmer MM, Ganz PA, et al. Primary care provider perceptions of barriers to and facilitators of colorectal cancer screening in a managed care setting. Cancer 2004;100:1843-52.

29. Hudon E, Beaulieu MD, Roberge D; Canadian Task Force on Preventive Health Care. Integration of the recommendations of the Canadian Task Force on Preventive Health Care: obstacles perceived by a group of family physicians. Fam Pract 2004;21:11-7.

30. University of Minnesota Evidence Based Practice Center. Economic incentives for preventive care. Rockville (MD): Agency for Healthcare Research and Quality; 2005. Available: www.ahrq.gov/clinic/epcsums/ecincsum.htm (accessed 2011 Nov. 21).

31. Gravelle H, Sutton M, Ma A. Doctor behaviour under a pay for performance contract: Treating, cheating and case finding? Econ J 2010;120:F129-56

32. Parchman ML, Burge SK. The patient-physician relationship, primary care attributes, and preventive services. Fam Med 2004; 36:22-7.

33. Lemon SC, Zapka JG, Puleo E. Comprehensive cancer screening in a primary care population: gender differences in the impact of ambulatory care system factors. J Ambul Care Manage 2005;28:86-97.

34. National Research Council. The prevention and treatment of missing data in clinical trials. Washington (DC): National Academies Press; 2010. p. 65.

Affiliations: From the Department of Family Medicine (Dahrouge, Hogg, Russell, Tuna, Muldoon, Fletcher), University of Ottawa, C.T. Lamont Primary Health Care Research Centre, Ottawa, Ont.; the Southern Academic Primary Care Research Unit (Russell), Monash University, Melbourne, Australia; the International Development Research Centre (Geneau), Ottawa, Ont:; and the School of Psychology (Kristjansson), Institute of Population Health, University of Ottawa, Ottawa, Ont.

Contributors: William Hogg, Laura Muldoon and Betsy Kristjansson conceived the original study with others and oversaw its implementation. They helped with the analysis and participated in the writing of the manuscript. Grant Russell helped oversee the implementation of the project, helped guide the analysis and participated in the writing of the manuscript. Simone Dahrouge was responsible for the quantitative data collection and analysis and oversaw the writing of the manuscript. Robert Geneau participated in the analysis and participated in the writing of the manuscript. Meltem Tuna performed the data analysis and participated in the writing of the manuscript. John Fletcher advised on the analysis and interpretation of the data and participated in drafting and writing the manuscript. All of the authors approved the final version of the manuscript submitted for publication. William Hogg acts as guarantor.

Funding: Funding of the original study on which this research is based was provided by the Primary Health Care Transition Fund of the Ontario Ministry of Health and LongTerm Care. The views expressed in this report are the views of the authors and do not necessarily reflect those of the Ontario Ministry of Health and Long-Term Care. 